\title{
Disbursement of Credit by KSFC to Agro and Non-Agro Industries in Karnataka: A critical economic analysis
}

\author{
Hiregouda Nagaraj ${ }^{1}$ and B.S. Reddy ${ }^{2 *}$ \\ ${ }^{1}$ Department of Agricultural Economics, University of Agricultural Sciences, Raichur-584 102, Karnataka, India \\ ${ }^{2}$ College of Agriculture, Kalaburagi-101, Karnataka, India \\ *Corresponding author: bsreddyagecon@gmail.com
}

\begin{abstract}
KSFC is providing financial assistance to the priority sector with maximum emphasis on food processing industries. The purposive sampling technique was adopted in designing sampling frame for the study. The Hyderabad -Karnataka region was purposively selected, which is industrially a backward region of the state. The secondary data were collected from KSFC branch offices of selected districts and states as a whole for a period of 14 years from 2000-01 to 2014-15. Compound growth rate analysis indicated that growth in number of units sanctioned and loan amount disbursed for agro-industries were 0.16 and 13.08 per cent per annum and were significant in H-K region. Similar trend of growth was observed in disbursement of loan to non-agro industries. The share of agro based industries in the total number of units sanctioned and credit disbursed by KSFC in H-K region was 35.39 and 44.96 per cents respectively. However, share of ABI's was very low with 16.39 and 12.91 per cents for number of units sanctioned and credit disbursed at the state level during the study period. The total number of micro, small and medium enterprises(MSME) of the sanctioned agro based industries indicated that $\mathrm{H}-\mathrm{K}$ region accounted 33.78 and 12.31 per cents of total ABI's and non-ABI units sanction by KSFC in the state.
\end{abstract}

Keywords: KSFC, Growth, Agro industries, Micro, Small, Medium

Karnataka State Financial Corporation (KSFC) is a state level financial institution established by the State Government in the year 1959 under the State Financial Corporation Act 1951 to cater to the long term financial needs of small and medium enterprises (SME) in the state of Karnataka. KSFC has contributed significantly to the growth of small scale industries (SSI), development of backward regions and promotion of first generation entrepreneurs in the state. It is one of the fast track term lending financial institutions in the country with assistance to over 1,69,244 units amounting to nearly ₹ 13,811 crores over the last 56 years (Annon, 2015). KSFC is one of the robust and professionally managed state financial corporations.

In the late 90s, the corporation went through a correction mode. This coincided with the impact of globalization and liberalization on the MSMEs. Being the prima-dona for the MSMEs in the state, the corporation had to take severe economic beating due to the fall of MSMEs in the state in the post liberalization era. However, with committed support of the major stakeholders namely Government of Karnataka and SIDBI, the Corporation bounced back to good health from the year 2003-04.

KSFC is providing financial assistance to the priority sector with maximum emphasis on food processing industries. Furthermore, ministry of food processing is also giving subsidy through KSFC for the establishment of agro-industries. It has given financial assistance to establish many agro industries namely rice mills, dal mills, rice bran solvent extraction units, chilli plants, dairy plants, seed processing, sugar industries, cold storage, warehouse, construction of godowns, etc. It is also acting as a facilitator between NAFED, NABARD, State Government, Central Government and AgroEntrepreneur. 
KSFC acts as an agent of the Central Government, the State Government, the IDBI, the IFCI or any other financial institutions notified by the Central Government with respect to any matter connected with, or arising out of the grant of loans or advances to any industrial concern, or subscription to debentures of an industrial concern or relating to the business of the IDBI, SIDBI, IFCI or any other financial institution.

The main objective of the study is to analyze the growth performance of Karnataka State Financial Corporation's (KSFC) in providing financial assistance to SSI in liberalized era. The study is analytical in nature, throwing light on the financing pattern of SSI sector by KSFC. Over the last 50 years, KSFC is one of the robust and professionally managed state financial corporations. It has contributed significantly for the growth of small scale industries (SSIs), backward area development and promotion of first generation entrepreneurs. It's achievement in these areas is unparallel (Anon, 2015a).

The new industrial policy announced by Government of Karnataka for the year 2014-2019 has given special emphasis for the development of Hyderabad-Karnataka region with the allocation of additional fund for the development of agroindustries. Keeping this in view, an attempt has been made to study the growth performance of KSFC with special reference to agro based industries in $\mathrm{H}-\mathrm{K}$ region.

\section{METHODOLOGY}

The purposive sampling technique was adopted in designing sampling frame for the study. The Hyderabad -Karnataka region was purposively selected with all the KSFC branches falling under this region. The secondary data were collected from KSFC branch offices of selected district for a period of 14 years from 2000-01 to 2014-15. The data collected were presented in a tabular form to facilitate easy comparison. This technique of tabular presentation was employed to compile the general and socio-economic characteristics of respondents with simple statistical tools like averages, ratios and percentages, which were computed to interpret the results properly.

\section{Compound growth rate analysis}

In order to assess the trend in sanction and disbursement of loan by selected KSFC branches, the compound growth rate analysis was employed. Compound growth rates were computed using the exponential function of the form,

$$
Y_{t}=a b^{t} u
$$

Where,

$$
\begin{aligned}
& Y_{t} \text { : Dependent variable } \\
& \text { a: Intercept constant } \\
& \text { b: Regression coefficient } \\
& t \text { : Years which take values, } 1,2, \ldots, n \\
& u_{t} \text { : Disturbance term for the year } t
\end{aligned}
$$

For the purpose of estimation, equation (1) was transformed into log linear form and coefficients were estimated using Ordinary Least Square (OLS) technique. The compound growth rate $(\mathrm{g})$ in percentage was then computed from the following relationship,

$$
\mathrm{g}=(\text { Antilog of } \ln \mathrm{b}-1) * 100 .
$$

The regression coefficient were tested for their significance level using, ' $t$ ' test which was defined as,

$$
|t|=\frac{b i}{S E(b i)} \sim t n-1
$$

Where,

bi= Regression coefficient

SE $($ bi) $=$ Standard error of the regression coefficient

$\mathrm{n}-1=$ Degrees of freedom

\section{RESULTS AND DISCUSSION}

The status of industries in Hyderabad Karnataka region (Table 1) revealed that the numbers of industries, especially small scale industry were lesser in number compared to other part of the state. This might be due to the imbalance in regional development, poor infrastructure facilities like rail and road connectivity to major cities of the state, non availability of raw material etc. Further, among the different districts of $\mathrm{H}-\mathrm{K}$ region, majority of the industrial areas were located in Ballari followed by Kalaburagi, Yadgir, Bidar, Raichur and Koppal districts. The $\mathrm{H}-\mathrm{K}$ region includes about 22 industrial 
Table 1: Industrial scenario of the study area

\begin{tabular}{|c|c|c|c|c|c|c|c|c|}
\hline \multirow{2}{*}{$\begin{array}{l}\text { Sl. } \\
\text { No. }\end{array}$} & \multirow{2}{*}{ Particulars } & \multicolumn{7}{|c|}{ Name of the district } \\
\hline & & Kalaburagi & Bidar & Yadgir & Raichur & Ballari & Koppal & $\mathrm{H}-\mathrm{K}$ region total \\
\hline \multirow{2}{*}{1} & Registered small scale & 18189 & 8327 & 861 & 10168 & 20084 & 7154 & 64783 \\
\hline & & $(28.08)$ & (12.85) & (1.33) & $(15.70)$ & $(31.00)$ & $(11.04)$ & (100.00) \\
\hline 2 & $\begin{array}{l}\text { Estimated avg. no. of } \\
\text { daily worker employed in } \\
\text { small scale industries }\end{array}$ & 78011 & 47023 & 3100 & 49007 & 101854 & 42933 & 321928 \\
\hline 3 & $\begin{array}{l}\text { Employment in large and } \\
\text { medium industries }\end{array}$ & 5577 & 1864 & 215 & 3564 & 4822 & 3991 & 20033 \\
\hline 4 & Number of industrial area & 4 & 2 & 4 & 4 & 6 & 2 & 22 \\
\hline
\end{tabular}

Note: Figures in parenthesis indicate per cent $H-K$ region total.

Table 2: Size wise number of units sanctioned by KSFC during study period (2000-2014)

\begin{tabular}{cccccccccc}
\hline S1. & \multirow{2}{*}{ District } & \multicolumn{3}{c}{ Agro based Industries (ABI) } & \multicolumn{3}{c}{ Non-Agro based Industries (Non-ABI) } \\
\cline { 3 - 9 } No. & Micro & Small & Medium & Total & Micro & Small & Medium & Total \\
\hline & Bidar & $27(7.44)$ & $9(1.97)$ & $7(4.24)$ & $43(4.37)$ & $31(5.35)$ & $112(9.92)$ & $11(8.87)$ & $153(8.35)$ \\
& Kalaburagi & $62(17.08)$ & $49(10.72)$ & $18(10.91)$ & $129(13.10)$ & $124(21.42)$ & $186(16.47)$ & $34(27.42)$ & $344(18.78)$ \\
& Yadgir & $5(1.38)$ & $13(2.84)$ & $5(3.03)$ & $23(2.34)$ & $19(3.28)$ & $50(4.43)$ & $5(4.03)$ & $74(4.04)$ \\
& Raichur & $42(11.57)$ & $89(19.47)$ & $15(9.09)$ & $146(14.82)$ & $77(13.30)$ & $164(14.53)$ & $15(12.10)$ & $256(13.97)$ \\
& Ballari & $143(39.39)$ & $109(23.85)$ & $56(33.94)$ & $308(31.27)$ & $148(25.56)$ & $262(23.21)$ & $31(25.00)$ & $442(24.13)$ \\
& Koppal & $84(23.14)$ & $188(41.14)$ & $64(38.79)$ & $336(34.11)$ & $180(31.09)$ & $355(31.44)$ & $28(22.58)$ & $563(30.73)$ \\
& H-K region & $363(32.01)$ & $457(34.54)$ & $165(35.95)$ & $985(33.78)$ & $579(12.77)$ & $1129(12.09)$ & $124(12.20)$ & $1832(12.31)$ \\
Karnataka & 1134 & 1323 & 459 & 2916 & 4534 & 9336 & 1016 & 14886 \\
\hline
\end{tabular}

Note: 1 . Figures in parenthesis indicate per cent respective H-K region total; $2{ }^{*}=$ Figures in parenthesis indicate per cent respective Karnataka's total.

areas of which majority are located in Ballari district (6) followed by Kalaburagi (4), Yadgir (4), Bidar (2) and Koppal (2). The size of small scale industries in the region indicated that Ballari district has the highest number of small scale industries (20084) with an employment of 101854 persons. Further, Kalaburagi district comprises of 18189 units of small scale industries with an employment of 78011, followed by Raichur (10168), Bidar (8327), Koppal (7154) and Yadgir (861) districts. In case of medium and large size industries, Kalaburagi district has the highest number of units (5577), followed by Ballari (4822), Koppal (3991), Raichur (3564), Bidar (1854) and Yadgir (215). Similarly, the size of the small scale industries was highest in Ballari district (20084), which provided employment to 101854 persons. In Kalaburagi, 18189 small scale industries were established, which have given employment to 78011. Similar trend of small scale industries and employment pattern were observed in other districts of $\mathrm{H}-\mathrm{K}$ region.
Table 2 indicated size wise number of units sanctioned by KSFC during the study period. Totally, 985 MSME AB1 units were sanctioned in $\mathrm{H}-\mathrm{K}$ region constituting 863,457 and 165 micro, small and medium enterprises respectively. The AB1 share in the total number of units sanctioned in Karnataka (2196 units) accounted 33.78 per cent of the state total MSME unit sanctioned by KSFC. Whereas in case of non-AB1, H-K region accounted only 12.31 per cent. Similar trend was observed across the size of units in the non-ABI sector. This shows that the share of $\mathrm{AB} 1$ was significantly higher (33.78\%) compared to non-ABI sector (12.31\%).

The Analysis across the districts of $\mathrm{H}-\mathrm{K}$ region indicated that in case of ABI, Koppal accounted the major share of 34.11 per cent followed by Ballari (31.27\%), Raichur (14.82\%), Kalaburagi (13.10\%), Bidar $(4.37 \%)$ and Yadgir $(2.34 \%)$. In case of nonAB1 sector, similar trend of share across the district of $\mathrm{H}-\mathrm{K}$ region was observed. 
The size wise number of units and credit disbursed were also higher in $\mathrm{H}-\mathrm{K}$ region. The KSFC has disbursed loan to 985 MSME out of the 2916 units sanctioned in the Karnataka state as a whole. This implies that across the size of the unit, $\mathrm{H}-\mathrm{K}$ region accounted for 33.78 per cent of the state total MSME units sanctioned by KSFC. Whereas under the nonagro industries category, $\mathrm{H}-\mathrm{K}$ region accounted only about 12.31 per cent of the state MSME sanctioned by KSFC. The findings clearly indicated that maximum number of units of MSME of ABI have availed loan compared to non ABI's in the study area. The findings of the study are in accordance with Elumalia Kannan's (2011) study on relationship between agricultural credit policy, disbursement and crop productivity in Karnataka.

The highest share of Koppal and Ballari in total
MSME might be due to the establishment of small units of paddy processing units, food products, spinning and weaving of textile units which require lesser investment. Similar result were reported by Laxmikanth Reddy and Ratna Kumari (2014), who studied the performance of agro based industries in India wherein agro based industries accounted for a major share in the National GDP.

The disbursement of credit by KSFC increased over the years from ₹ 3262.85 lakh in 2000-01 to ₹ 15067.83 lakh in 2013-14. Similarly, share of agro based industries in the total disbursement also showed an increasing trend with mild fluctuations. The overall share of $\mathrm{ABI}$ in total number of units sanctioned and loan amount disbursement in $\mathrm{H}-\mathrm{K}$ region were 35.37 and 44.96 per cent of the state total number of units sanctioned and loan amount

Table 3: Share of Agro based Industries (ABI) in total disbursement of KSFC

\begin{tabular}{|c|c|c|c|c|c|c|}
\hline \multirow[t]{2}{*}{ Year } & \multicolumn{2}{|c|}{ Share of ABI (\%) } & \multicolumn{2}{|c|}{ Share of Non-ABI (\%) } & \multicolumn{2}{|c|}{ Total } \\
\hline & Number & Loan value & Number & Loan value & Number & Loan value (₹ Lakh) \\
\hline \multicolumn{7}{|c|}{ H-K region } \\
\hline $2000-01$ & 30.77 & 35.85 & 69.23 & 64.15 & 221 & 3162.85 \\
\hline 2003-04 & 19.91 & 26.33 & 80.09 & 73.67 & 226 & 3029.43 \\
\hline 2004-05 & 32.13 & 44.60 & 67.87 & 55.40 & 221 & 3019.02 \\
\hline $2005-06$ & 41.79 & 53.55 & 58.21 & 46.45 & 201 & 3887.16 \\
\hline 2006-07 & 37.61 & 55.79 & 62.39 & 44.21 & 226 & 4624.56 \\
\hline $2007-08$ & 41.15 & 47.80 & 58.85 & 52.20 & 209 & 4153.60 \\
\hline 2008-09 & 45.36 & 59.29 & 54.64 & 40.71 & 183 & 7412.00 \\
\hline $2009-10$ & 50.49 & 64.21 & 49.51 & 35.79 & 204 & 7703.50 \\
\hline 2010-11 & 41.78 & 52.00 & 58.22 & 48.00 & 213 & 10708.25 \\
\hline 2011-12 & 40.41 & 40.33 & 59.59 & 59.67 & 193 & 9213.75 \\
\hline $2012-13$ & 30.53 & 41.01 & 69.47 & 58.99 & 285 & 14891.60 \\
\hline 2013-14 & 26.36 & 36.30 & 73.64 & 63.70 & 258 & 15067.83 \\
\hline 2014-15 & 21.47 & 27.37 & 78.53 & 72.63 & 177 & 9978.00 \\
\hline Overall & 35.37 & 44.96 & 64.63 & 55.04 & 2817 & 96851.55 \\
\hline \multicolumn{7}{|c|}{ Karnataka } \\
\hline 2000-01 & 13.81 & 9.49 & 86.19 & 90.51 & 1405 & 33303.98 \\
\hline 2003-04 & 11.32 & 9.09 & 88.68 & 90.91 & 1307 & 29969.76 \\
\hline 2004-05 & 16.26 & 15.16 & 83.74 & 84.84 & 1242 & 24175.95 \\
\hline 2005-06 & 18.96 & 15.38 & 81.04 & 84.62 & 1234 & 31620.50 \\
\hline $2006-07$ & 18.63 & 13.19 & 81.37 & 86.81 & 1326 & 42452.94 \\
\hline 2007-08 & 19.02 & 13.52 & 80.98 & 86.48 & 1267 & 36815.07 \\
\hline 2008-09 & 18.57 & 16.68 & 81.43 & 83.32 & 1422 & 57212.06 \\
\hline 2009-10 & 17.73 & 14.46 & 82.27 & 85.54 & 1461 & 63148.75 \\
\hline 2010-11 & 16.53 & 13.95 & 83.47 & 86.05 & 1537 & 73162.62 \\
\hline 2011-12 & 16.63 & 11.03 & 83.37 & 88.97 & 1485 & 81731.68 \\
\hline $2012-13$ & 15.21 & 12.44 & 84.79 & 87.56 & 1598 & 94405.52 \\
\hline 2013-14 & 15.36 & 12.22 & 84.64 & 87.78 & 1426 & 90926.05 \\
\hline 2014-15 & 15.02 & 11.23 & 84.98 & 88.77 & 1092 & 67514.60 \\
\hline Overall & 16.39 & 12.91 & 83.61 & 87.09 & 17802 & 726439.50 \\
\hline
\end{tabular}


Table 4: Growth in disbursement of loan by KSFC in H-K region and Karnataka during study period (Per cent)

\begin{tabular}{cccccccc}
\hline \multirow{2}{*}{$\begin{array}{c}\text { Sl. } \\
\text { No. }\end{array}$} & District & \multicolumn{2}{c}{ Agro based Industries (ABI) } & \multicolumn{2}{c}{ Non-Agro based Industries (Non-ABI) } & \multicolumn{2}{c}{ Total } \\
\cline { 3 - 7 } & & Number & Loan Value & Number & Loan Value & Number & Loan Value \\
\hline 1 & Bidar & $11.09^{*}$ & $24.60^{*}$ & $1.30^{*}$ & $18.30^{* *}$ & $2.71^{* *}$ & $18.86^{*}$ \\
2 & Kalaburagi & $4.04^{*}$ & $19.07^{*}$ & $-2.66^{*}$ & $11.30^{* *}$ & -1.17 & $12.00^{*}$ \\
3 & Yadgir & -2.20 & -11.36 & $49.25^{*}$ & $5.57^{*}$ & 18.56 & -1.74 \\
4 & Raichur & $-1.82^{* *}$ & $10.86^{* *}$ & -6.45 & $-1.87^{* *}$ & -4.93 & $7.26^{* *}$ \\
5 & Ballari & -0.68 & $15.50^{*}$ & $-0.56^{*}$ & $8.68^{*}$ & -0.26 & $9.67^{*}$ \\
6 & Koppal & -0.40 & $9.54^{* *}$ & $-4.10^{*}$ & $12.27^{*}$ & $-0.73^{*}$ & $13.27^{*}$ \\
7 & H-K region & $0.16^{*}$ & $13.08^{*}$ & -0.10 & 10.51 & 0.95 & $10.92^{*}$ \\
8 & Karnataka & -2.28 & $6.13^{*}$ & -3.78 & $4.70^{* *}$ & -3.80 & $4.62^{* *}$ \\
\hline
\end{tabular}

Note: ${ }^{* * *}=$ Significant @1 per cent level of significance; ${ }^{* *}=$ Significant @5 per cent level of significance; ${ }^{*}=$ Significant @10 per cent level of significance.

disbursed, respectively. However, the share of nonagro based industries showed a declining trend in the study area, this might be due to the dominance of cereals and pulses in the study area particularly redgram and bengalgram in Kalaburagi district, greengram and blackgram in Bidar district, cotton and paddy in Yadgir, Raichur, Ballari and Koppal districts. Therefore, there is a need to establish tur park in Kalaburagi district, cotton textile park in Yadgir and Raichur area and rice park in Ballari and Koppal area.

It is important to note that though there is an increase in number of units sanctioned as well as loan amount disbursed in the state as a whole, the percentage of loan sanctioned to agro based industries was 16.39 and 12.91 per cent of the total number of unit and amount disbursed respectively. The findings indicated that there is a scope for growth in agro based industries in other part of the state also. Therefore, the Government should formulate policies in order to encourage agro based industries in the state as a whole. Similar findings were reported by Sahu (2007), who conducted a study on intuitional credit to agriculture.

The share of ABI in total loan disbursed by KSFC during the study period was ₹ 726439.50 lakh to about 17802 industries indicating 16.39 per cent in the state as whole. This is clear from the findings that KSFC has neglected agro based industries in the state as a whole. However, H-K region had shown a different trend compared to the state revealing 44.96 per cent of loan disbursed by KSFC diverted towards agro based industries.
The comparison of growth in disbursement of loan to industries in H-K region and Karnataka indicated opposite trends. However, growth in amount sanctioned for establishing agro based industries was higher in $\mathrm{H}-\mathrm{K}$ region compared to Karnataka state as a whole. The higher growth in ABI's in $\mathrm{H}-\mathrm{K}$ region might be due to increase in area under pulses, cereals and commercial crops, which led to establishment of large number of dal mills, rice mills and cotton ginning mills. The industry wise sanction and disbursement of loan by KSFC to different ABI's in $\mathrm{H}-\mathrm{K}$ region indicated imbalance growth across the district and across the agro based industries.

In case of Bidar district, positive growth was noticed in disbursement of loan to number of dal mills units and others industries were positive and significant. The Kalaburagi district had shown positive growth in disbursement of loans by KSFC to dal mills. Similarly, Yadgir district KSFC branch has not disbursed loan to rice mills as well as other mills, hence negative growth was observed in the number of units sanctioned as well as loan amount disbursed. This might be due to the recent establishment of new district and there was no much awareness about the KSFC lending credit to micro and small scale industries by the respondents. The growth in disbursement of loan by KSFC to different agro based industries in Raichur district indicated positive and significant growth in establishing number of units and amount disbursed. However, disbursement to rice mills and other industries has been reduced mainly due to shift in cropping pattern and majority of farmers have undertaken 
cultivation of cotton on larger scale by replacing paddy area.

It is worth to note that KSFC branch of Ballari district has disbursed loan to maximum number of cotton ginning mills and other non-ABI units, which have shown positive growth trend in terms of number of units sanctioned and loan amount disbursed. However, growth in disbursement of loan to rice mill has shown a declining trend in terms of number of units sanctioned, whereas loan amount disbursed had shown a positive trend. This might be due to the shift in cropping pattern in the district from paddy to cotton because of scarcity of water during rabi and summer season. In case of Koppal KSFC branch, negative growth in number units was sanctioned and disbursed for establishing rice mills, parboiled rice mills and rice mill dries. However positive growth was observed in the establishment of other non-ABI units.

\section{CONCLUSION}

The growth in disbursement of loan to number of agro industry units and loan value increased significantly during the study period in $\mathrm{H}-\mathrm{K}$ region and Karnataka state as a whole. Similar trend of growth was observed in disbursement of loan amount to non-agro industries. The share of agro based industries in the total sanction by KSFC in H-K region was 35.39 and 44.96 per cents for number of unit sanction and its loan value respectively. However, share of ABI's was very low with 16.39 and 12.91 per cents for number of units and its loan value at the state level during the study period indicating potentiality of agro industry in the $\mathrm{H}-\mathrm{K}$ region. The total number of micro, small and medium enterprises of agro based industries during the study period indicated that $\mathrm{H}-\mathrm{K}$ region accounts 33.78 and 12.31 per cents of total ABI's and non-ABI sanction respectively by KSFC in the state. From the forgoing analysis it is imperative that a similar effort is to be made to develop state level policy in general and $\mathrm{H}-\mathrm{K}$ region in particular laying down the role of agro based industry, planners and promoters, financial institution, expert of DIC, marketers and other share holders involved in the task. Therefore, NABARD should come forward to provide financial assistance for establishing Agro Industry in the backward region of the state wherein cereal and pulses are dominated in the region.

\section{REFERENCES}

Anonymous, 2015. Annual report Karnataka state financial corporation, Bangaluru, pp. 7-14.

Anonymous, 2015a. Karnataka agribusiness and food processing policy with special reference to Hyderabad Karnataka region. Karnataka state financial corporation, news report, 6(3): 21-26.

Elumalai, K. 2011, Relationship between agricultural credit policy, credit disbursements and crop productivity: A study in Karnataka. Indian J. Agric. Econ., 66(3): 445-455.

Laxmikantreddy and Ratna Kumari, S. 2014, Performance of Agro based industries in India: A critical analysis. J. Econ and Finance, 2(4): 15-25.

Sahu, G.B. 2007, Supply analysis of institutional credit to agriculture in major states in India. Indian J. Agric. Econ., 62(4): 665-678. 